\title{
Transition State for $\beta$-Elimination of Hydrogen from Alkoxy Groups on Metal Surfaces
}

\author{
Andrew J. Gellman,* Mark T. Buelow, ${ }^{\dagger}$ and Shane C. Street \\ Department of Chemical Engineering, Carnegie Mellon University, Pittsburgh, Pennsylvania 15213
}

\author{
Thomas Hellman Morton \\ Department of Chemistry, University of California, Riverside, California 92521-0403
}

Received: September 28, 1999; In Final Form: January 11, 2000

\begin{abstract}
Experimental investigations of $\beta$-hydrogen elimination from alkoxy and alkyl groups bound to a $\mathrm{Cu}(111)$ surface have been coupled with computational studies of gas-phase analogues to provide insight into the transition state for catalytic hydrogenation and dehydrogenation on metal surfaces. Previous studies have shown that fluorination increases the activation barrier $\left(\Delta E_{\text {act }}\right)$ to $\beta$-hydrogen elimination in ethoxy groups $\left(\mathrm{RCH}_{2} \mathrm{O}_{(\mathrm{ad})} \rightarrow \mathrm{RCH}=\mathrm{O}_{(\mathrm{ad})}+\mathrm{H}_{(\mathrm{ad})}\right.$, where $\left.\mathrm{R}=\mathrm{CH}_{3}, \mathrm{CFH}_{2}, \mathrm{CHF}_{2}, \mathrm{CF}_{3}\right)$ and propyl groups $\left(\mathrm{RCH}_{2} \mathrm{CH}_{2, \text { (ad) }} \rightarrow\right.$ $\mathrm{RCH}=\mathrm{CH}_{2 \text {,(ad) }}+\mathrm{H}_{(\mathrm{ad})}$, where $\mathrm{R}=\mathrm{CH}_{3}, \mathrm{CF}_{3}$ ) on the $\mathrm{Cu}(111)$ surface. The increase in barrier height with increasing fluorination was attributed to the inductive influence of fluorine, which energetically destabilizes a hydride-like transition state of the form $\left[\mathrm{RC}^{\delta+} \cdot{ }^{-} \mathrm{H}^{\delta-}\right]^{\ddagger}$. In this paper, deuterium kinetic isotope effects (DKIE) show that fluorination does not alter the mechanism for $\beta$-hydrogen elimination from ethoxy groups. Furthermore, the DKIE measurements confirm that the effects of fluorine on the kinetics of $\beta$-hydrogen elimination do not result from the change in mass when hydrogen is substituted by fluorine. A systematic study of fluorine substitution of surface-bound isopropoxy groups reveals combined steric and electronic effects. An excellent correlation is found between the $\Delta E_{\text {act }}$ for $\beta$-hydrogen elimination in adsorbed alkoxy groups and the calculated reaction energetics $\left(\Delta H_{\mathrm{rxn}}\right)$ for gas-phase dehydrogenation of fluorinated alcohols in trans antiperiplanar conformations (e.g., $\mathrm{RCH}_{2} \mathrm{OH}_{(\mathrm{g})} \rightarrow \mathrm{RCH}=\mathrm{O}_{(\mathrm{g})}+\mathrm{H}_{2,(\mathrm{~g})}$, where the hydroxyl hydrogen is antiperiplanar to a carbon and the oxygen is antiperiplanar to a fluorine). Hammett plots for $\beta$-hydrogen elimination give a reaction parameter of $\rho=-26$. These correlations both suggest that the transition state for $\beta$-hydrogen elimination develops a greater partial positive charge on the carbinol carbon than is found in the adsorbed reactant. Furthermore, the transition state is energetically late in the reaction coordinate for $\beta$-hydrogen elimination.
\end{abstract}

\section{Introduction}

The transition states for elementary steps of surface-catalyzed reactions ultimately dictate the overall reaction kinetics of complex catalytic processes. $\beta$-Hydrogen elimination has served as an ideal prototype reaction for exploring the use of substituent effects in the study of transition states on surfaces. ${ }^{1,2}$ Moreover, $\beta$-hydrogen elimination is an important reaction in its own right. It is observed in the decomposition of alkoxy groups and alkyl groups on many metal surfaces. ${ }^{3,4}$ The microscopic reverse of $\beta$-hydrogen elimination also constitutes the initial step in catalytic hydrogenation. ${ }^{5}$ Ultimately, a deeper knowledge of the nature of the transition state for $\beta$-hydrogen elimination offers an opportunity to understand the influence of various catalytic surfaces on this very common elementary reaction. Here, we present results that clarify several points in our current understanding of the barrier to $\beta$-hydrogen elimination and further refine the picture of the transition state.

Previous work using substituent effects to probe the nature of the transition state for $\beta$-hydrogen elimination examined the reaction in substituted ethoxy and $n$-propyl groups bound to

\footnotetext{
* Author to whom correspondence should be addressed.

Current address: Department of Materials Science, University of Delaware, Newark, DE 19716.

$\doteqdot$ Current address: Department of Chemistry, University of Alabama, Tuscaloosa, AL 35487.
}

the $\mathrm{Cu}(111)$ surface, eqs 1 and 2.,2 These experiments used temperature-programmed reaction spectra (TPRS) to measure activation barriers $\left(\Delta E_{\text {act }}\right)$ for $\beta$-hydrogen elimination in these ethoxy and $n$-propyl groups as a function of fluorine substitution.

$$
\begin{aligned}
& \mathrm{RCH}_{2} \mathrm{O}-\mathrm{Cu} \rightarrow \mathrm{RCH}=\mathrm{O}_{(\mathrm{ad})}+\mathrm{H}-\mathrm{Cu} \\
& \mathrm{R}=\mathrm{CF}_{3}, \mathrm{CHF}_{2}, \mathrm{CFH}_{2}, \mathrm{CH}_{3} \\
& \mathrm{RCH}_{2} \mathrm{CH}_{2}-\mathrm{Cu} \rightarrow \mathrm{RCH}=\mathrm{CH}_{2,(\mathrm{ad})}+\mathrm{H}-\mathrm{Cu} \\
& \mathrm{R}=\mathrm{CF}_{3}, \mathrm{CH}_{3}
\end{aligned}
$$

In the case of the ethoxy species, fluorination of the methyl group systematically increases the $\Delta E_{\text {act }}$ by $55 \mathrm{~kJ} \mathrm{~mol}^{-1}$ from $121 \pm 4 \mathrm{~kJ} \mathrm{~mol}^{-1}$ to $176 \pm 6 \mathrm{~kJ} \mathrm{~mol}^{-1}$. In the case of $n$-propyl groups, perfluorination of the terminal methyl group increases the activation barrier by $\Delta \Delta E_{\mathrm{act}}=35 \pm 3 \mathrm{~kJ} \mathrm{~mol}^{-1}$. The experiments on ethoxy groups gave very similar results on $\mathrm{Cu}(100), \mathrm{Cu}(110)$, and $\mathrm{Ag}(110)$ surfaces, revealing that the fluorine substituent effect does not display sensitivity to the structure of the surface or the nature of the metal. However, it is important to note that although the magnitude of the substituent effect $\left(\Delta \Delta E_{\text {act }}\right)$ is similar on $\mathrm{Cu}$ and $\mathrm{Ag}$ surfaces, the absolute values of the $\Delta E_{\text {act }}$ are quite different.

The fluorine substituent effect on the $\Delta E_{\text {act }}$ for $\beta$-hydrogen elimination has been rationalized in terms of a hydride-like 
transition state $\left[\mathrm{RC}^{\delta+} \cdot \cdot \mathrm{H}^{\delta-}\right]^{\ddagger}$, in which the carbon atom is electron deficient. The inductive effect of the fluorine in the methyl groups serves to energetically destabilize such a transition state. The implication of this interpretation was that the electron deficient nature of the carbon atom resulted from charge compensation with the hydrogen leaving group. Within that model for the transition state it was not clear why the perfluorination of methyl has a greater effect in the case of an ethoxy group $\left(\Delta \Delta E_{\text {act }}=55 \mathrm{~kJ} \mathrm{~mol}^{-1}\right)$ than in the case of $n$-propyl $\left(\Delta \Delta E_{\text {act }}=35 \mathrm{~kJ} \mathrm{~mol}^{-1}\right)$. The observations made in the work reported here rationalize this effect.

One intriguing aspect of the measured values of $\Delta E_{\text {act }}$ for $\beta$-hydrogen elimination is that they are more sensitive to fluorine substituent effects than the thermochemical energies $\left(\Delta H_{\mathrm{rxn}}\right)$ of ethanol and propane dehydrogenation, eqs 3 and 4. Unfortunately, experimental $\Delta H_{\mathrm{rxn}}$ for dehydrogenation are not available for all the fluorine-substituted ethanols and propanes that need be considered if one wishes to make direct comparison of $\Delta H_{\mathrm{rxn}}$ to the $\Delta E_{\text {act }}$ measured for $\beta$-hydrogen elimination in the corresponding ethoxy and propyl groups. Some relevant numbers are available. If the published theoretical prediction of the heat of formation (at $298 \mathrm{~K}$ ) of gaseous trifluoroacetaldehyde ${ }^{6}$ is combined with the experimental $\Delta H_{\mathrm{f}}^{0}$ for trifluoroethanol, ${ }^{7}$ the estimated heat of reaction for the dehydrogenation of trifluoroethanol to trifluoroacetaldehyde is $\Delta H_{\mathrm{rxn}}=114 \mathrm{~kJ}$ $\mathrm{mol}^{-1}$. This is substantially greater than the experimental value for the heat of ethanol dehydrogenation to acetaldehyde, $\Delta H_{\mathrm{rxn}}$ $=69 \mathrm{~kJ} \mathrm{~mol}^{-1} \cdot{ }^{7}$ Those data lead to a ratio of $\Delta \Delta E_{\mathrm{act}} / \Delta \Delta H_{\mathrm{rxn}}$ $=1.2$ for the dehydrogenation of ethanols. For the case of trifluoropropane dehydrogenation (eq 4), one can obtain the $\Delta H_{\mathrm{rxn}}=143 \mathrm{~kJ} \mathrm{~mol}^{-1}$ from an estimated $\Delta H_{\mathrm{f}}^{0}$ of $1,1,1-$ trifluoropropane $\left(-757 \mathrm{~kJ} \mathrm{~mol}^{-1}\right)^{8}$ and the experimental $\Delta H_{\mathrm{f}}^{0}$ for 1,1,1-trifluoropropene. ${ }^{7}$ The experimental value for the dehydrogenation of propane is $\Delta H_{\mathrm{rxn}}=124 \mathrm{~kJ} \mathrm{~mol}^{-1}$. $^{7}$ Comparing these to the measured $\Delta E_{\text {act }}$ for $\beta$-hydrogen elimination in propyl and trifluoropropyl groups on the $\mathrm{Cu}(111)$ surface ${ }^{2}$ leads to a ratio of $\Delta \Delta E_{\mathrm{act}} / \Delta \Delta H_{\mathrm{rxn}}=1.8$. Since experiment has shown that fluorination of the methyl does not greatly perturb the binding energies of ethoxy groups to metal surfaces, ${ }^{1}$ the fact that these $\Delta \Delta E_{\mathrm{act}} / \Delta \Delta H_{\mathrm{rxn}}$ ratios are $\geq 1$ cannot be attributed to reactant state stabilization. In other words, the transition state energies for $\beta$-hydrogen elimination appear to be more greatly influenced by fluorine substitution than the net $\Delta H_{\mathrm{rxn}}$ of eqs 3 and 4 . Since the $\Delta \Delta E_{\mathrm{act}} / \Delta \Delta H_{\mathrm{rxn}}$ ratios are based on numbers obtained from widely disparate estimation procedures, it is not easy to evaluate their quantitative significance. Consequently, this paper explores the relationship between experimental $\Delta E_{\text {act }}$ and estimates of $\Delta H_{\mathrm{rxn}}$ based on a consistent set of DFT calculations. We find that $\Delta E_{\text {act }}$ varies roughly linearly with $\Delta H_{\mathrm{rxn}}$ as fluorine is added to ethoxy groups, with nearly the same proportionality constant as for propyl groups (once the appropriate molecular conformations are taken into account). The $\Delta \Delta E_{\text {act }} / \Delta \Delta H_{\text {rxn }}$ ratios are much closer to one another than the above estimates would suggest, which in turn implies that the apparent differences between $\beta$-hydrogen elimination in alkoxy and alkyl groups mask an underlying parallelism in substituent effects.

$$
\begin{aligned}
& \mathrm{RCH}_{2} \mathrm{OH} \rightarrow \mathrm{RCH}=\mathrm{O}+\mathrm{H}_{2} \\
& \mathrm{R}=\mathrm{CF}_{3}, \mathrm{CHF}_{2}, \mathrm{CFH}_{2}, \mathrm{CH}_{3} \\
& \mathrm{RCH}_{2} \mathrm{CH}_{3} \rightarrow \mathrm{RCH}=\mathrm{CH}_{2}+\mathrm{H}_{2} \quad \mathrm{R}=\mathrm{CF}_{3}, \mathrm{CH}_{3}
\end{aligned}
$$

The correspondence between fluorine substituent effects on $\Delta E_{\text {act }}$ for $\beta$-hydrogen elimination in alcohols and $\Delta H_{\mathrm{rxn}}$ for gas- phase alcohol dehydrogenation becomes apparent only when suitable rotamer structures are chosen for the fluorinated alcohols. The favored geometry of gaseous trifluoroethanol, for instance, brings the $\mathrm{O}-\mathrm{H}$ group close to one of the fluorine atoms, with a hydrogen-fluorine distance of $2.56 \AA .{ }^{9}$ The analogous structure does not seem realistic for a trifluoroethoxy group adsorbed on a surface. Imposition of appropriate conformational constraints on the gas-phase ethanols reveals a correlation between the $\Delta H_{\mathrm{rxn}}$ for gas-phase dehydrogenation and the $\Delta E_{\text {act }}$ for $\beta$-hydrogen elimination in ethoxy groups. That insight provides a deeper understanding of the nature of the transition state for this extremely important elementary surface reaction.

Complementing the investigations that probe the electronic structure of the transition state for $\beta$-hydrogen elimination, published studies also shed light on the structure of the adsorbed reactant states. The structure of the ethoxy reactant has been determined using Fourier transform infrared reflection-absorption spectroscopy (FT-IRAS). ${ }^{10}$ On the $\mathrm{Cu}(111)$ surface, ethoxy is oriented with its $\mathrm{C}-\mathrm{C}$ bond roughly parallel to the plane of the surface and the $\mathrm{O}-\mathrm{C}-\mathrm{C}$ plane of the molecule tilted by approximately $20^{\circ}$ with respect to the surface normal. This structure looks like that proposed for ethoxy on the $\mathrm{Ni}(111)$ surface. ${ }^{11}$ More importantly, it bears a great similarity to that proposed for trifluoroethoxy on the $\mathrm{Cu}(111)$ surface. ${ }^{12}$ The fact that adsorbed ethoxy and trifluoroethoxy both have nearly the same orientations suggests that differences in reactant geometry are not responsible for the effects of fluorination on the $\Delta E_{\mathrm{act}}$ to $\beta$-hydrogen elimination. Furthermore, the observation that the methylene stretch modes have similar frequencies in both ethoxy and trifluoroethoxy indicates that the $\mathrm{C}-\mathrm{H}$ bond strength is not influenced significantly by fluorination. ${ }^{10,12}$

Steric effects on the transition state for $\beta$-hydrogen elimination have been probed by a study of the kinetics in a series of cyclic alkyl groups on the $\mathrm{Cu}(100)$ surface. ${ }^{13}$ The $\Delta E_{\text {act }}$ to $\beta$-hydrogen elimination in cyclohexyl groups is observed to be $23 \mathrm{~kJ} \mathrm{~mol}^{-1}$ higher than in either cyclopentyl or cycloheptyl groups. A number of arguments have been advanced to attribute this primarily to the differences in the energies needed to achieve a planar configuration of the $\mathrm{Cu}-\mathrm{C}-\mathrm{C}-\mathrm{H}$ bonds in the adsorbed alkyl. Both cyclopentyl and cycloheptyl groups have stable structures, which are very close in energy to this configuration. In the cyclohexyl group, which can adopt highly nonplanar "twist-boat" or "chair" conformations, the energy needed to achieve planarity is approximately $23 \mathrm{~kJ} / \mathrm{mol}$ and would account entirely for the differences observed in the barriers to $\beta$-hydrogen elimination. The planar structure of the transition state is also predicted by computational models. ${ }^{14}$

This paper provides additional experimental results that address both the mechanism and the nature of the transition state for $\beta$-hydrogen elimination. Studies of deuterium isotope effects reported here confirm that the mechanism does not change in going from ethoxy to trifluoroethoxy and that the effects of fluorination on the barrier to $\beta$-hydrogen elimination do not exhibit significant contributions that can be attributed to the mass or steric bulk of fluorine.

Additional measurements enlarge the set of alkoxy groups for which the $\Delta E_{\text {act }}$ has been measured. $\beta$-Hydrogen elimination from adsorbed isopropoxy groups to form ketones (eq 5) increases the variety of substituents directly attached to the carbinol carbon. With this expanded set of compounds, it has been possible to correlate $\Delta E_{\text {act }}$ with Hammett substituent constants (both $\sigma_{\mathrm{F}}$ and $\left.\sigma_{\mathrm{p}}\right)^{15}$ as well as with gas phase $\Delta H_{\mathrm{rxn}}$ for alcohol dehydrogenation. This approach demonstrates an 
empirical means of quantifying the effects of substituents that in the future can be applied to a wider variety of surface reactions.

$$
\begin{array}{r}
\mathrm{R}^{\prime} \mathrm{RCHO}-\mathrm{Cu} \rightarrow \mathrm{R}^{\prime} \mathrm{RCH}=\mathrm{O}_{(\mathrm{ad})}+\mathrm{Cu}-\mathrm{H} \\
\qquad \mathrm{R}, \mathrm{R}^{\prime}=\mathrm{CF}_{3}, \mathrm{CH}_{3}
\end{array}
$$

\section{Experimental Section}

The experiments described in this paper were performed in a stainless steel ultrahigh vacuum (UHV) chamber. A base pressure of $<10^{-10}$ Torr is achieved by means of a cryopump and a titanium sublimation pump. The chamber is equipped with an $\mathrm{Ar}^{+}$sputter gun, an electron gun, a retarding field analyzer for Auger electron spectroscopy, and a quadrupole mass spectrometer for both background gas analysis and temperatureprogrammed reaction spectroscopy (TPRS). The chamber has leak valves for backfilling with gas or vapor and a capillary array gas doser for line-of-sight exposure of the $\mathrm{Cu}(111)$ surface to vapor. Exposures are reported in Langmuirs $\left(1 \mathrm{~L}=1 \times 10^{-6}\right.$ Torr s) and are not corrected for differences in ion gauge sensitivity. It should be noted that for the gases used in this work the multiplication factor when using the capillary array is $\sim 20$.

The $\mathrm{Cu}(111)$ single crystal was obtained from Monocrystals Inc. It was mounted on a sample holder by spot-welding between two tantalum wires. The sample holder was attached to a manipulator allowing precise $x$-, $y$-, and $z$-axis travel and $360^{\circ}$ rotation of the crystal inside the chamber. Once mounted on the manipulator the sample was in mechanical contact with a liquid nitrogen reservoir. The crystal could be cooled to $T<$ $100 \mathrm{~K}$ and resistively heated to $T>1000 \mathrm{~K}$. Sample temperature measurement was made using a chromel-alumel thermocouple spot-welded to the edge of the crystal. During heating the sample temperature was controlled by a computer.

Cleaning of the $\mathrm{Cu}(111)$ surface followed standard procedures. The surface was cleaned by cycles of heating to $1000 \mathrm{~K}$ while $\mathrm{Ar}^{+}$ion sputtering and by exposure to large doses $(\sim 100$ L) of oxygen at $800 \mathrm{~K}$ to remove carbon. After each experiment involving the formation and reaction of adsorbed alkoxy the crystal was annealed to $1000 \mathrm{~K}$ to dissolve any carbon left by alkoxy decomposition into the bulk of the crystal. The crystal surface was judged to be clean if no impurities were detected by AES.

Adsorbed alkoxy groups were formed by exposing the clean $\mathrm{Cu}(111)$ surface to high background exposures of oxygen with the crystal at $600 \mathrm{~K}$ followed by exposure to the corresponding alcohol through the capillary array with the crystal at $250 \mathrm{~K}$. Holding the crystal at $250 \mathrm{~K}$ during exposure to the alcohol allowed the reaction of the alcohol with the adsorbed oxygen to form the alkoxy while the coproduct, water, desorbed. Saturation of the surface with a given alkoxy species was achieved when the aldehyde yield in the subsequent TPRS measurement was maximized. The alcohol exposure in each case was greater than that required to react with the available adsorbed oxygen (usually $0.1 \mathrm{~L}$ of the alcohol when dosing through the capillary array) so that the oxygen exposure was the factor limiting the amount of alkoxy that was formed on the surface. The maximum yields of the aldehydes occurred for oxygen exposures in the range 30-70 L (uncorrected background). The amount of oxygen required to routinely achieve the maximum yield of aldehyde was dependent on the initial cleanliness of the surface and bulk of the crystal. Some of the oxygen scavenged adsorbed carbon which was left behind as a minor decomposition product by prior reaction of adsorbed alkoxy to aldehyde. The kinetics of the $\beta$-hydrogen elimination reaction on the $\mathrm{Cu}(111)$ surface are relatively insensitive to alkoxy coverage making minor variations unimportant. ${ }^{1}$

The quadrupole mass spectrometer used for desorption measurements was shrouded by a stainless steel tube with a stainless steel cone as an aperture to the ionizer. The diameter of the aperture was slightly smaller than the diameter of the $\mathrm{Cu}(111)$ sample $(\sim 1 \mathrm{~cm})$. Desorption measurements were made by positioning the sample $2-3 \mathrm{~mm}$ from the front of the aperture and then heating the sample while monitoring ion fragments, usually the parent aldehyde, with the mass spectrometer. Heating was controlled by computer, using a proportional/differential feedback routine to maintain a constant heating rate.

The alcohols used in this work were $\mathrm{CH}_{3} \mathrm{CH}_{2} \mathrm{OH}, \mathrm{CH}_{3} \mathrm{CD}_{2}$ $\mathrm{OH}, \mathrm{CF}_{3} \mathrm{CH}_{2} \mathrm{OH}, \mathrm{CF}_{3} \mathrm{CD}_{2} \mathrm{OH}, \mathrm{CH}_{3} \mathrm{CHDOH},\left(\mathrm{CF}_{3}\right)_{2} \mathrm{CHOH}, \mathrm{CF}_{3}-$ $\mathrm{CH}(\mathrm{OH}) \mathrm{CH}_{3}$, and $\left(\mathrm{CH}_{3}\right)_{2} \mathrm{CHOH}$. The $\mathrm{CH}_{3} \mathrm{CHDOH}$ was synthesized by reducing acetaldehyde with $\mathrm{LiAlD}_{4}$ in ether, removing the solvent, quenching the reaction with excess dodecanol, and distilling ethanol- $d_{1}$ to afford a product that was $\geq 99$ at. \% D. Other materials were purchased from commercial sources. All compounds were degassed by several cycles of freezing, pumping, and thawing before introduction into the vacuum chamber, where their purity was checked by mass spectrometry.

\section{Computational}

Experimental thermodynamic values for dehydrogenation of fluorinated alkanes and alcohols have not been reported, so they were computed using G3 and DFT methods. The gas-phase heats of formation for unfluorinated alcohols and aldehydes agree well with G3 values. ${ }^{16} \mathrm{We}$ also note that $\Delta \Delta H_{\mathrm{rxn}}$ for dehydrogenation of trifluoropropane (whose heat of formation has not been determined experimentally and must be estimated by group equivalents) relative to propane is not badly fit by ab initio calculations. ${ }^{16}$

In the course of these computations, it was necessary to ascertain the most stable conformations of the alcohols and their corresponding aldehydes. Calculation of the geometry reveals that ethanol prefers an anti geometry, in agreement with experiment. The favored conformations of the fluoroethanols all have oxygen synclinal with a fluorine, again in conformity with experiment, with the $\mathrm{O}-\mathrm{H}$ hydrogen directed toward a fluorine. ${ }^{17-19}$

\section{Results}

Isotope Effects on $\boldsymbol{\beta}$-Hydrogen Elimination. Previous work to determine the nature of the transition state for $\beta$-hydrogen elimination has compared the values of $\Delta E_{\text {act }}$ in a set of fluorinated and unfluorinated ethoxy groups on $\mathrm{Cu}$ and $\mathrm{Ag}$ surfaces. ${ }^{1}$ This comparison is meaningful only if all of the ethoxy groups react by the same mechanism and via the same transition state. Thus, this investigation has examined deuterium kinetic isotope effects (DKIE) in order to test whether the TPR spectra do in fact measure the kinetics of the same rate-limiting step for both fluorinated and unfluorinated ethoxy groups. The observation of the same primary DKIE in the TPR spectra of $\beta$-hydrogen elimination in both ethoxy and trifluoroethoxy provides strong evidence that both react via the same mechanism.

To observe the DKIE for $\beta$-hydrogen elimination on the $\mathrm{Cu}(111)$ surface, the TPR spectra shown in Figure 1 were obtained for $\mathrm{CH}_{3} \mathrm{CH}_{2} \mathrm{O}_{(\mathrm{ad})}, \mathrm{CH}_{3} \mathrm{CD}_{2} \mathrm{O}_{(\mathrm{ad})}, \mathrm{CF}_{3} \mathrm{CH}_{2} \mathrm{O}_{(\mathrm{ad})}$, and $\mathrm{CF}_{3} \mathrm{CD}_{2} \mathrm{O}_{(\mathrm{ad})}$. These spectra were obtained by starting with saturated coverages of the ethoxy groups, as described previ- 


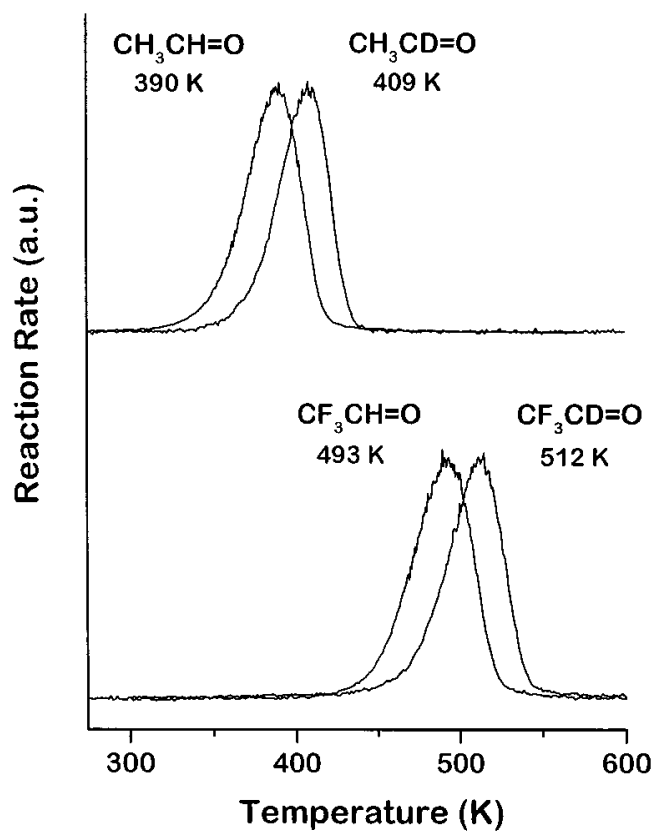

Figure 1. TPRS of $\mathrm{CH}_{3} \mathrm{CH}_{2} \mathrm{O}_{(\mathrm{ad})}, \mathrm{CH}_{3} \mathrm{CD}_{2} \mathrm{O}_{(\mathrm{ad})}, \mathrm{CF}_{3} \mathrm{CH}_{2} \mathrm{O}_{(\mathrm{ad})}$, and $\mathrm{CF}_{3} \mathrm{CD}_{2} \mathrm{O}_{(\mathrm{ad})}$ on the $\mathrm{Cu}(111)$ surface. The spectra were obtained by monitoring the parent ion of the acetaldehyde products generated by $\beta$-hydrogen elimination in the ethoxides. The peak desorption temperatures increase by $19 \mathrm{~K}$ on deuteration of the $\mathrm{C} 1$ carbon atom in both ethoxy and trifluoroethoxy. The fact that a deuterium kinetic isotope effect is observed in both cases indicates that $\beta$-hydrogen elimination is rate limiting in both cases. Heating rate $\beta=2 \mathrm{~K} / \mathrm{s}$.

ously, and then monitoring acetaldehyde or trifluoroacetaldehyde desorption during heating of the surface at a rate of $2 \mathrm{~K} / \mathrm{s}$. Because the rate constant for desorption of acetaldehyde is much higher than the rate constant for $\beta$-hydrogen elimination, these TPR spectra provide a measure of the $\beta$-hydrogen elimination reaction kinetics. ${ }^{20}$ It is immediately evident that deuteration of the carbon atom at the $\beta$-position with respect to the surface increases the temperature at which the reaction occurs. This temperature shift is approximately $19 \mathrm{~K}$ for both ethoxy and trifluoroethoxy. The isotope effect identifies $\beta$-hydrogen elimination as a kinetically significant step in the aldehyde production.

The DKIE can be quantified by determining the ratio of the rate constants for $\beta$-hydrogen elimination in the deuterium labeled and in the unlabeled ethoxy groups. By comparing the rates of acetaldehyde desorption from the TPR spectra of $\mathrm{CH}_{3} \mathrm{CH}_{2} \mathrm{O}_{(\mathrm{ad})}$ and $\mathrm{CH}_{3} \mathrm{CD}_{2} \mathrm{O}_{(\mathrm{ad})}$, one finds that $k_{\mathrm{H}, \mathrm{H}} / k_{\mathrm{D}, \mathrm{D}}=3.4$ \pm 0.6 at $390 \mathrm{~K}$. In this notation, the first subscript on the rate constant refers to the atom that is removed during $\beta$-hydrogen elimination and the second subscript refers to the atom remaining on the $\beta$-carbon atom. The temperature at which the reaction rate reaches its maximum is $390 \mathrm{~K}$ for $\mathrm{CH}_{3} \mathrm{CH}_{2} \mathrm{O}_{(\mathrm{ad})}$. This value of $k_{\mathrm{H}, \mathrm{H}} / k_{\mathrm{D}, \mathrm{D}}$ was determined by a technique referred to as the "direct method" by Madix et al. ${ }^{21}$ Briefly, $k_{\mathrm{H}, \mathrm{H}} / k_{\mathrm{D}, \mathrm{D}}=\left(r_{\mathrm{H}} / \theta_{\mathrm{H}}\right)$ $\left(\theta_{\mathrm{D}} / r_{\mathrm{D}}\right)$, where $r_{\mathrm{H}}$ is the rate of $\beta$ - $\mathrm{H}$ elimination and $r_{\mathrm{D}}$ is the rate of $\beta$-D elimination. At a given temperature, these are proportional to the amplitudes of the TPR spectra. The quantities $\theta_{\mathrm{H}}$ and $\theta_{\mathrm{D}}$ are the coverages of the corresponding alkoxy groups and are determined by integrating the TPR spectra. The advantage of this "direct method" is that absolute values of the activation energies and pre-exponential factors for the reaction need not be determined. The DKIE can be determined anywhere in the temperature range over which the two TPR spectra overlap. Assuming that the $\Delta E_{\text {act }}$ do not depend on coverage, the difference in barrier heights can be calculated by means of

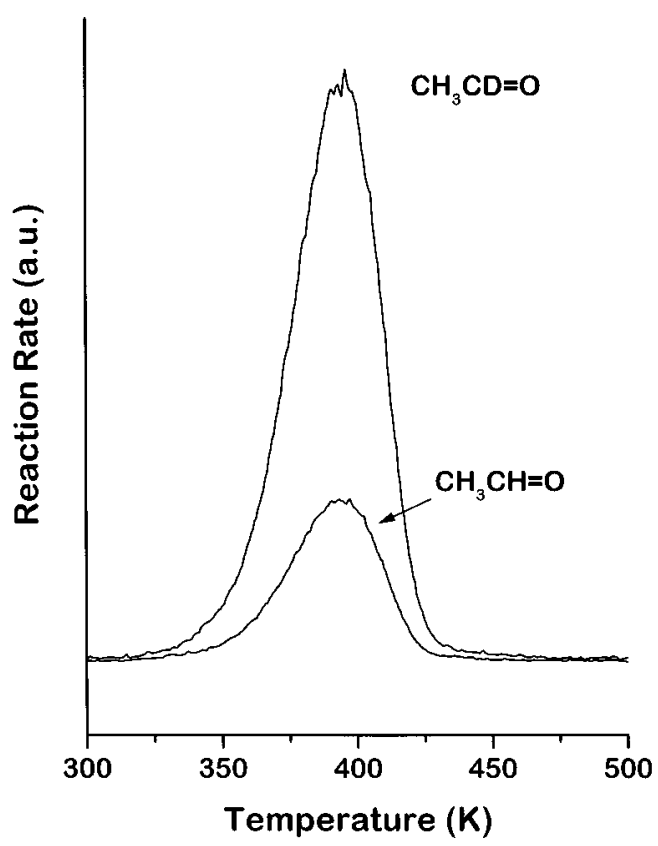

Figure 2. TPRS for $\mathrm{CH}_{3} \mathrm{CHDO}_{(\text {ad) }}$ on the $\mathrm{Cu}(111)$ surface. The spectra were obtained by monitoring the parent ion of acetaldehyde products. The ratio of the spectra of $\mathrm{CH}_{3} \mathrm{CD}=\mathrm{O}$ to $\mathrm{CH}_{3} \mathrm{CH}=\mathrm{O}$ is a measure of the deuterium kinetic isotope effect. The ratio of $\mathrm{CH}_{3} \mathrm{D}=\mathrm{O}$ to $\mathrm{CH}_{3} \mathrm{CH}=\mathrm{O}$ gives $k_{\mathrm{HD}} / k_{\mathrm{DH}}=3.6$ at $395 \mathrm{~K}$. Heating rate $\beta=2 \mathrm{~K} / \mathrm{s}$.

the mathematical relation $\Delta \Delta E_{\text {act }}=R T \ln \left(k_{\mathrm{H}, \mathrm{H}} / k_{\mathrm{D}, \mathrm{D}}\right)$, provided that we also assume that the preexponential factors are unchanged by isotopic labeling. This gives an estimate of $\Delta \Delta E_{\text {act }}$ $=4.0 \pm 0.7 \mathrm{~kJ} \mathrm{~mol}^{-1}$ for the ethoxy groups. That value is consistent with an isotope effect, which results from differences in the zero-point energy levels of the $v_{\mathrm{s}}\left(\mathrm{CD}_{2}\right)$ and $v_{\mathrm{S}}\left(\mathrm{CH}_{2}\right)$ vibrational modes of the adsorbed ethoxy groups. The frequencies of these modes can be obtained from the literature ${ }^{10}$ and are $v_{\mathrm{s}}\left(\mathrm{CH}_{2}\right)=2857 \mathrm{~cm}^{-1}$ and $\nu_{\mathrm{s}}\left(\mathrm{CD}_{2}\right)=2085 \mathrm{~cm}^{-1}$. These frequencies yield a predicted difference in the zero-point energies of $\Delta \Delta E_{\mathrm{act}}=4.8 \mathrm{~kJ} \mathrm{~mol}^{-1}$, in reasonable agreement with the value determined experimentally.

The DKIE has also been determined for $\beta$-hydrogen elimination in $\mathrm{CF}_{3} \mathrm{CH}_{2} \mathrm{O}_{(\mathrm{ad})}$ and $\mathrm{CF}_{3} \mathrm{CD}_{2} \mathrm{O}_{(\mathrm{ad})}$. The ratio of rate constants is $k_{\mathrm{H}, \mathrm{H}} / k_{\mathrm{D}, \mathrm{D}}=2.9 \pm 0.6$ at $493 \mathrm{~K}$, which yields a value of $\Delta \Delta E_{\mathrm{act}}$ $=4.4 \pm 0.8 \mathrm{~kJ} \mathrm{~mol}^{-1}$. As with the nonfluorinated ethoxy group, this is consistent with the difference in zero-point energy levels of the $v_{\mathrm{S}}\left(\mathrm{CH}_{2}\right)$ and $v_{\mathrm{S}}\left(\mathrm{CD}_{2}\right)$ vibrational modes. The frequencies of the vibrational modes reported in the literature ${ }^{12}$ are $v_{\mathrm{S}}\left(\mathrm{CH}_{2}\right)$ $=2937 \mathrm{~cm}^{-1}$ and $v_{\mathrm{S}}\left(\mathrm{CD}_{2}\right)=2087 \mathrm{~cm}^{-1}$, which yield an estimate of the difference in the zero point-energies of $\Delta \Delta E_{\text {act }}$ $=5.3 \mathrm{~kJ} \mathrm{~mol}^{-1}$. The presence of this kinetic isotope effect in both ethoxy and trifluoroethoxy and the approximately equal value of the zero-point energy differences clearly identifies $\beta$-hydrogen elimination as the rate-limiting step in the reactions of both. This is an important point since it justifies the comparison of the $\Delta E_{\text {act }}$ for $\beta$-hydrogen elimination in hydrocarbon and fluorocarbon alkoxy groups as a means of probing the transition state for this reaction.

In an independent set of experiments, the DKIE was determined by measuring the relative rate constants for $\beta-\mathrm{H}$ and $\beta$-D elimination in $\mathrm{CH}_{3} \mathrm{CHDO}_{(\mathrm{ad})}$ on the $\mathrm{Cu}(111)$ surface. The TPR spectra showing the desorption of $\mathrm{CH}_{3} \mathrm{CD}=\mathrm{O}$ and $\mathrm{CH}_{3} \mathrm{CH}=\mathrm{O}$ during reaction of a saturation coverage of $\mathrm{CH}_{3} \mathrm{CHDO}_{(\mathrm{ad})}$ are shown in Figure 2. The ratio of the yields of $\mathrm{CH}_{3} \mathrm{CD}=\mathrm{O}$ and $\mathrm{CH}_{3} \mathrm{CH}=\mathrm{O}$ produced by this reaction is a direct measure of the primary kinetic isotope effect. The first fact to 


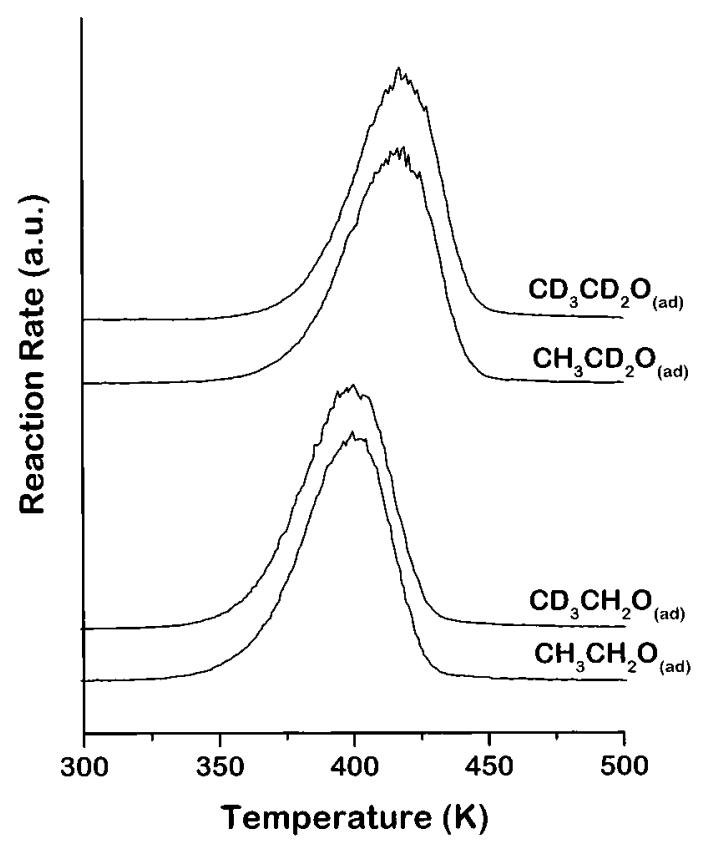

Figure 3. TPRS for $\mathrm{CH}_{3} \mathrm{CH}_{2} \mathrm{O}_{(\mathrm{ad})}, \mathrm{CD}_{3} \mathrm{CH}_{2} \mathrm{O}_{(\mathrm{ad})}, \mathrm{CD}_{3} \mathrm{CH}_{2} \mathrm{O}_{(\mathrm{ad})}$, and $\mathrm{CD}_{3} \mathrm{CD}_{2} \mathrm{O}_{(\mathrm{ad})}$ on the $\mathrm{Cu}(111)$ surface. The spectra were obtained by monitoring the parent ion of the acetaldehyde products. There is no observable effect of deuteration in the methyl group indicating that there is no secondary isotope effect. Heating rate $\beta=2 \mathrm{~K} / \mathrm{s}$.

note is that more $\mathrm{CH}_{3} \mathrm{CD}=\mathrm{O}$ desorbs than $\mathrm{CH}_{3} \mathrm{CH}=\mathrm{O}$, thus the rate of $\mathrm{C}-\mathrm{H}$ bond breaking is greater than the rate of $\mathrm{C}-\mathrm{D}$ bond breaking. These TPRS curves both reach a maximum at a temperature of $395 \mathrm{~K}$ for a heating rate of $2 \mathrm{~K} / \mathrm{s}$. By this method, $k_{\mathrm{H}, \mathrm{D}} / k_{\mathrm{D}, \mathrm{H}}=3.6$ at $395 \mathrm{~K}$ and implies that $\Delta \Delta E_{\mathrm{act}}=$ $4.2 \pm 0.8 \mathrm{~kJ} \mathrm{~mol}^{-1}$, which is in close agreement with the values calculated above.

During $\beta$-elimination in $\mathrm{CH}_{3} \mathrm{CHDO}_{\text {(ad) }}$ the isotope ( $\mathrm{H}$ or $\mathrm{D}$ ) that is left on the carbon atom depends on which isotope is eliminated $(\mathrm{D}$ or $\mathrm{H})$. When there are isotopic differences between atoms bound to the reaction center (other than the atom that is involved in the reaction), these differences can give rise to secondary isotope effects. The only way in which the use of $\mathrm{CH}_{3} \mathrm{CHDO}_{(\text {ad) }}$ and the comparison between $\mathrm{CH}_{3} \mathrm{CH}_{2} \mathrm{O}_{(\text {ad) }}$ and $\mathrm{CH}_{3} \mathrm{CD}_{2} \mathrm{O}_{\text {(ad) }}$ can yield equal primary isotope effects is if these secondary isotope effects are negligible, which is clearly the case. A previous study of secondary isotope effects on $\beta$-hydrogen elimination in methoxy groups on the $\mathrm{Cu}(110)$ surface also showed that secondary effects are very small. ${ }^{22}$

Secondary isotope effects resulting from deuterium substitution in the methyl group of ethoxy can be identified by comparing the kinetics of $\beta$-hydrogen elimination between $\mathrm{CH}_{3} \mathrm{CH}_{2} \mathrm{O}_{(\mathrm{ad})}$ and $\mathrm{CD}_{3} \mathrm{CH}_{2} \mathrm{O}_{(\mathrm{ad})}$ and between $\mathrm{CH}_{3} \mathrm{CD}_{2} \mathrm{O}_{(\mathrm{ad})}$ and $\mathrm{CD}_{3} \mathrm{CD}_{2} \mathrm{O}_{\text {(ad) }}$. Figure 3 shows TPR spectra of the desorption of acetaldehyde produced from $\beta$-hydrogen elimination of these ethoxy groups. These spectra were collected at saturation coverage of the ethoxy and at a heating rate of $2 \mathrm{~K} / \mathrm{s}$. The absence of any change in peak temperature due to methyl group deuteration indicates clearly that the secondary isotope effects from substitution vicinal to the reacting center are immeasurable. This is relevant to our comparison of $\beta$-hydrogen elimination in substituted alkoxy groups, since it indicates that effects purely due to atomic mass $\left(m_{\mathrm{F}}=19\right.$ versus $\left.m_{\mathrm{H}}=1\right)$ can be neglected.

Electronic Substituent Effects on $\boldsymbol{\beta}$-Hydrogen Elimination. The $\Delta E_{\text {act }}$ for $\beta$-hydrogen elimination in several alkoxy and fluorinated alkoxy groups were measured in order to probe the nature of the transition state. The use of highly electronegative
TABLE 1: Kinetic Parameters and Substituent Constants, $\sigma_{\mathrm{F}}$, for $\beta$-Hydride Elimination on the $\mathrm{Cu}(111)$ Surface $^{a}$

\begin{tabular}{lllllllc}
\hline $\begin{array}{c}\text { adsorbed } \\
\text { reactant }\end{array}$ & $\begin{array}{c}\text { substit- } \\
\text { uents }\end{array}$ & $\sigma_{\mathrm{p}}$ & $\sum \sigma_{\mathrm{p}}$ & $\sigma_{\mathrm{F}}$ & $\sum \sigma_{\mathrm{F}}$ & $\begin{array}{c}\log _{10} v \\
\left(\mathrm{~s}^{-1}\right)\end{array}$ & $\begin{array}{c}\Delta E_{\text {act }} \\
\left(\mathrm{kJ} \mathrm{mol}^{-1}\right)\end{array}$ \\
\hline $\mathrm{CH}_{3} \mathrm{O}$ & $\mathrm{H}$ & 0.0 & 0.0 & 0.0 & 0.0 & 16.2 & 136 \\
& $\mathrm{H}$ & 0.0 & & 0.0 & & & \\
$\mathrm{CH}_{3} \mathrm{CH}_{2} \mathrm{O}$ & $\mathrm{H}$ & 0.0 & -0.17 & 0.0 & 0.0 & 15.2 & 121 \\
& $\mathrm{CH}_{3}$ & -0.17 & & 0.0 & & & \\
$\mathrm{CFH}_{2} \mathrm{CH}_{2} \mathrm{O}$ & $\mathrm{H}$ & 0.0 & 0.11 & 0.0 & 0.22 & 16.0 & 138 \\
& $\mathrm{CFH}$ & 0.11 & & 0.22 & & & \\
$\mathrm{CF}_{2} \mathrm{HCH}_{2} \mathrm{O}$ & $\mathrm{H}$ & 0.0 & 0.29 & 0.0 & 0.36 & 16.2 & 146 \\
& $\mathrm{CF}_{2} \mathrm{H}$ & 0.29 & & 0.36 & & & \\
$\mathrm{CF}_{3} \mathrm{CH}_{2} \mathrm{O}$ & $\mathrm{H}$ & 0.0 & 0.54 & 0.0 & 0.44 & 17.9 & 176 \\
& $\mathrm{CF}_{3}$ & 0.54 & & 0.44 & & & \\
$\left(\mathrm{CH}_{3}\right)_{2} \mathrm{CHO}$ & $\mathrm{CH}_{3}$ & -0.17 & -0.34 & 0.0 & 0.0 & 14.3 & 114 \\
& $\mathrm{CH}_{3}$ & -0.17 & & 0.0 & & & \\
$\left(\mathrm{CF}_{3}\right) \mathrm{CH}(\mathrm{CH})_{3} \mathrm{O}$ & $\mathrm{CH}_{3}$ & -0.17 & 0.37 & 0.0 & 0.44 & 17.8 & 174 \\
& $\mathrm{CF}_{3}$ & 0.54 & & 0.44 & & & \\
$\left(\mathrm{CF}_{3}\right)_{2} \mathrm{CHO}$ & $\mathrm{CF}_{3}$ & 0.54 & 1.08 & 0.44 & 0.88 & 23.3 & 264 \\
& $\mathrm{CF}_{3}$ & 0.54 & & 0.44 & & &
\end{tabular}

${ }^{a}$ The kinetic parameters were determined by fitting variable heating rate TPRS data to the model; rate $=v \exp \left(-\Delta E_{\text {act }} / R T\right) \theta$, where $\theta$ is the alkoxy coverage. Addition of fluorine to the methyl substituent increases the $\Delta E_{\text {act }}$.

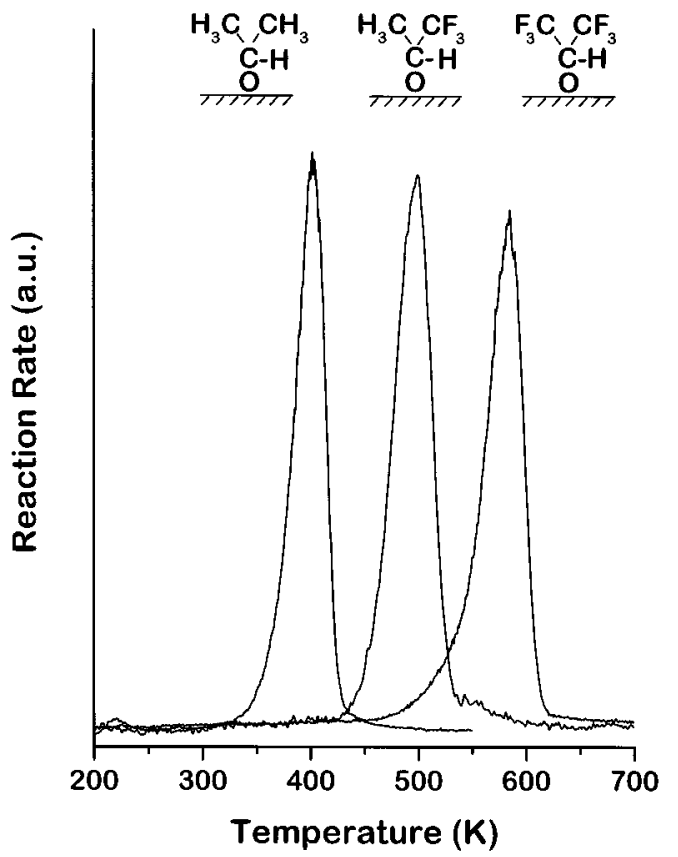

Figure 4. TPRS of $\left(\mathrm{CH}_{3}\right)_{2} \mathrm{CHO}_{(\mathrm{ad})},\left(\mathrm{CF}_{3}\right)\left(\mathrm{CH}_{3}\right) \mathrm{CHO}_{(\mathrm{ad})}$, and $\left(\mathrm{CF}_{3}\right)_{2} \mathrm{CHO}_{(\mathrm{ad})}$ on the $\mathrm{Cu}(111)$ surface. The spectra were obtained by monitoring the parent ion of the acetone products generated by $\beta$-hydrogen elimination in the reactant alkoxides. Fluorination substantially increases the peak desorption temperature indicating an increase in the barrier to $\beta$-hydrogen elimination. Heating rate $\beta=2$ $\mathrm{K} / \mathrm{s}$.

fluorine as a substituent can have a dramatic effect on the $\Delta E_{\mathrm{act}}$ if there is a difference in the charge density at the reaction center on going from the reactant to the transition state. The work reported here expands the set of alkoxy groups for which the $\Delta E_{\text {act }}$ to $\beta$-hydrogen elimination has been measured on the $\mathrm{Cu}$ (111) surface. The previously measured values of $\Delta E_{\text {act }}$ for methoxy and ethoxy groups are listed in Table 1. In this work the $\Delta E_{\text {act }}$ for $\beta$-hydrogen elimination in isopropoxy groups, eq 5 , have also been measured. The TPR spectra of acetone and fluorinated acetones produced by $\beta$-hydrogen elimination in these isopropoxy groups are shown in Figure 4. These were collected at saturation coverage of the isopropoxy and using a heating rate of $2 \mathrm{~K} / \mathrm{s}$. Each of the trifluoromethyl groups 


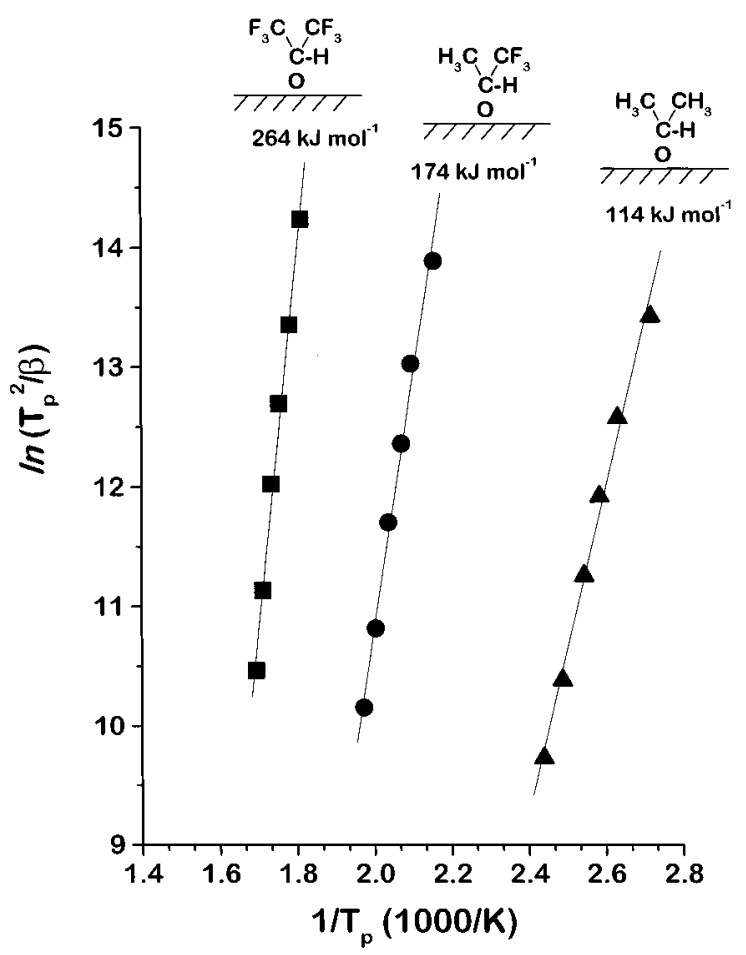

Figure 5. Plots of $\ln \left(T_{\mathrm{p}}^{2} / \beta\right)$ versus $1 / T_{\mathrm{p}}$ for the TPR spectra of isopropoxy groups on the $\mathrm{Cu}(111)$ surface $\left(T_{\mathrm{p}}\right.$, peak desorption temperature; $\beta$, heating rate). The heating rate was varied from $\beta=$ 0.2 to $10 \mathrm{~K} / \mathrm{s}$. The slopes give the activation barriers for $\beta$-hydrogen elimination.

increases the temperature of the product desorption peak in the TPR spectra by roughly $100 \mathrm{~K}$. Clearly the fluorination of the methyl groups of isopropoxy causes a substantial increase in the $\Delta E_{\text {act }}$ for $\beta$-hydrogen elimination.

To estimate the $\Delta E_{\text {act }}$ for $\beta$-hydrogen elimination, TPR spectra have been obtained for each of the isopropoxy groups at heating rates in the range $0.2-10 \mathrm{~K} / \mathrm{s}$. These variable heating rate spectra can be analyzed to give the $\Delta E_{\text {act }}$ without the need to assume a value for the pre-exponential factor in the rate constant for $\beta$-hydrogen elimination. Figure 5 shows plots of $\ln \left(T_{\mathrm{p}}^{2} / \beta\right)$ versus $1 / T_{\mathrm{p}}$ for the three isopropoxy groups, where $\beta$ symbolizes the heating rate. The values of $\Delta E_{\text {act }}$ are determined from the slopes of these plots and are listed in Table 1 with the pre-exponential factors. The effects of fluorine substitution on the $\Delta E_{\text {act }}$ to $\beta$-hydrogen elimination of the secondary alkoxy groups agree qualitatively with those observed in the ethoxy species, increasing systematically with the degree of fluorine substitution of the methyl groups.

Electronic Substituent Effects on Alcohol Dehydrogenation. To understand the effects of fluorine substitution on the energetics of the transition state for $\beta$-hydrogen elimination, it has been instructive to compare this reaction (eq 1) to comparable reactions in the gas phase. $\beta$-Hydrogen elimination (eq 1) and alcohol dehydrogenation (eq 3 ) are analogous in the sense that both produce the same unsaturated products, but in one case the hydrogen atom forms $\mathrm{Cu}-\mathrm{H}$ while in the other case it forms $\mathrm{H}_{2}$. Since very few experimental values have been reported for the dehydrogenation energies $\left(\Delta H_{\mathrm{rxn}}\right)$ of the fluorine-substituted alcohols in eq 3 they have been calculated here for a variety of reactant conformations. In addition electronic energy changes $\left(\Delta E^{\mathrm{el}}\right)$ have been calculated for the gas-phase elimination of lithium hydride from lithium ethoxides, eq 6. Values of $\Delta H_{\mathrm{rxn}}$ for dehydrogenation of propane and trifluoropropane have also been calculated, to make a compari- son with the effects of fluorine substitution on the $\Delta E_{\text {act }}$ for $\beta$-hydrogen elimination in propyl groups on the $\mathrm{Cu}(111)$ surface. $^{2}$

$$
\mathrm{RCH}_{2} \mathrm{O}-\mathrm{Li} \rightarrow \mathrm{RCH}=\mathrm{O}+\mathrm{Li}-\mathrm{H}
$$

The $\Delta H_{\mathrm{rxn}}$ for dehydrogenation of alcohols and alkanes given in Table 2 were estimated using G3 and DFT calculations and compared to values obtained from thermochemical tables. ${ }^{7} \mathrm{G} 3$ theory is reported to give excellent values for the $\Delta H_{\mathrm{f}, 298}^{0}$ of ethanol, 2-propanol, acetaldehyde, and acetone, ${ }^{16}$ but we find that the $\Delta H_{\mathrm{f}, 298}^{0}$ for trifluoroethanol predicted by G3 theory $\left(859 \mathrm{~kJ} \mathrm{~mol}^{-1}\right)$ does not agree well with the reported experimental value $\left(888 \mathrm{~kJ} \mathrm{~mol}^{-1}\right) .^{7}$ Nor does the G3 prediction of $\Delta H_{\mathrm{f}, 298}^{0}$ for trifluoroacetaldehyde agree well with the theoretical value calculated using BAC-MP4 theory. ${ }^{23}$ Nevertheless the G3 value of $\Delta \mathrm{H}_{\mathrm{rxn}}=112 \mathrm{~kJ} \mathrm{~mol}^{-1}$ for trifluoroethanol dehydrogenation is in good agreement with the value of $\Delta H_{\text {rxn }}$ $=114 \mathrm{~kJ} \mathrm{~mol}^{-1}$ predicted from the experimental $\Delta H_{\mathrm{f}, 298}^{0}$ for trifluoroethanol and the theoretical BAC-MP4 $\Delta H_{\mathrm{f}, 298}^{0,28}$ for trifluoroacetaldehyde. We need only the relative values, $\Delta H_{\mathrm{rxn}}$, for heats of dehydrogenation of the fluorinated alcohols. Hence, although the $\Delta H_{\mathrm{f}, 298}^{0}$ for the fluorinated alcohols are not as close to the experimental values as one might like, the $\Delta H_{\mathrm{rxn}}$ predicted by G3 theory are deemed to be sufficiently accurate for the purposes of this work.

The most important observation of the calculations is that $\Delta H_{\mathrm{rxn}}$ for alcohol dehydrogenation increases systematically with the degree of fluorination of the methyl groups. This agrees with the observed effect of fluorination on the experimental $\Delta E_{\text {act }}$ for $\beta$-hydrogen elimination in alkoxy groups on the $\mathrm{Cu}(111)$ surface. For purposes of establishing a correlation between the $\Delta H_{\mathrm{rxn}}$ and the $\Delta E_{\text {act }}$, we make use of electronic energy differences $\left(\Delta E^{\mathrm{el}}\right)$ between reactants and products of alcohol dehydrogenation calculated using DFT. We neglect contributions from zero-point energy changes because, as Table 2 summarizes, they are nearly the same for all the reactions under consideration. For similar reasons, we do not include corrections for basis set superposition error. While the absolute values of $\Delta E^{\mathrm{el}}$ predicted by DFT are substantially higher than the G3 values for $\Delta H_{\mathrm{rxn}}$, a plot of one versus the other gives a straight line (slope $=1.05, r^{2}=0.98$ ). Thus, we believe that estimating $\Delta \Delta H_{\mathrm{rxn}}$ by using the DFT values for $\Delta \Delta E^{\mathrm{el}}$ is just as suitable as using values predicted by G3 theory for exploring the relationship between thermodynamics of alcohol dehydrogenation and the $\Delta E_{\text {act }}$ to $\beta$-hydrogen elimination in alkoxy groups.
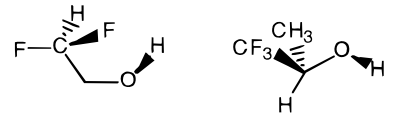

more stable, synclinal conformations

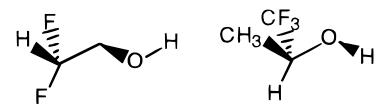

trans antiperiplanar conformations
The values of $\Delta H_{\mathrm{rxn}}$ for alcohol dehydrogenation depend on the conformations of the reactants and the products. It is quite possible that the most stable gas-phase conformations of the fluorinated alcohols are not analogous to the conformations adopted by the fluorinated alkoxy groups on the $\mathrm{Cu}(111)$ surface. When the most stable conformers of the substituted ethanols are used as reactants a plot of experimental $\Delta E_{\text {act }}$ for $\beta$-hydrogen elimination versus calculated values of $\Delta E^{\mathrm{el}}$ for alcohol dehydrogenation gives a poor correlation, regardless of whether G3 or DFT values are used for the thermochemistry. Likewise, $\Delta E_{\text {act }}$ does not correlate well with $\Delta E^{\mathrm{el}}$ calculated for gas-phase 
TABLE 2: Calculated Gas-Phase Endothermicities for Dehydrogenation of Alcohols and of Loss of LiH from Lithium Alkoxides (All Energies in $\mathbf{k J ~ m o l}^{-1}$ )

\begin{tabular}{|c|c|c|c|c|c|}
\hline \multirow[b]{2}{*}{ reaction } & \multirow{2}{*}{$\begin{array}{c}\mathrm{G} 3 \text { theory }^{a} \\
\Delta H_{\mathrm{Y}=\mathrm{H}}^{298}\end{array}$} & \multicolumn{4}{|c|}{$\begin{array}{l}\text { density functional theory } \\
\text { (B3LYP/6-311G**) }\end{array}$} \\
\hline & & $\Delta E_{\mathrm{Y}=\mathrm{Li}}^{\mathrm{el}}$ & $\Delta E_{\mathrm{Y}=\mathrm{H}}^{\mathrm{el}}$ & $\mathrm{BSSE}^{b}$ & $\triangle \mathrm{ZPE}^{c}$ \\
\hline $\mathrm{CH}_{3} \mathrm{OY} \rightarrow \mathrm{CH}_{2} \mathrm{O}$ & 88 & 252 & 111 & 8 & -38 \\
\hline $\mathrm{CH}_{3} \mathrm{CH}_{2} \mathrm{OY} \rightarrow \mathrm{CH}_{3} \mathrm{CHO}$ & $67^{a}$ & 232 & 83 & 8 & -38 \\
\hline $\mathrm{FCH}_{2} \mathrm{CH}_{2} \mathrm{OY} \rightarrow \mathrm{FCH}_{2} \mathrm{CHO}$ & 87 & $\begin{array}{l}276 \\
(251 \text { anti })^{d}\end{array}$ & $\begin{array}{l}106 \\
(96 \text { anti })^{d}\end{array}$ & 8 & -40 \\
\hline $\mathrm{F}_{2} \mathrm{CHCH}_{2} \mathrm{OY} \rightarrow \mathrm{F}_{2} \mathrm{CHCHO}$ & 103 & $\begin{array}{l}292 \\
(280 \text { anti })^{d}\end{array}$ & $\begin{array}{l}122 \\
\left(112 \text { anti }^{d}\right.\end{array}$ & 8 & -38 \\
\hline $\mathrm{CF}_{3} \mathrm{CH}_{2} \mathrm{OY} \rightarrow \mathrm{CF}_{3} \mathrm{CHO}$ & 112 & $\begin{array}{l}299 \\
\left(299 \text { anti }^{d}\right.\end{array}$ & $\begin{array}{l}129 \\
\left(119 \text { anti }^{d}\right.\end{array}$ & 8 & -38 \\
\hline$\left(\mathrm{CH}_{3}\right)_{2} \mathrm{CHOY} \rightarrow\left(\mathrm{CH}_{3}\right)_{2} \mathrm{CO}$ & $55^{a}$ & 211 & 68 & 7 & -38 \\
\hline $\mathrm{CF}_{3}\left(\mathrm{CH}_{3}\right) \mathrm{CHOY} \rightarrow \mathrm{CF}_{3}\left(\mathrm{CH}_{3}\right)_{2} \mathrm{CO}$ & & $\begin{array}{l}273 \\
(273 \text { anti })^{d}\end{array}$ & $\begin{array}{l}106 \\
(96 \text { anti })^{d, e}\end{array}$ & 11 & -37 \\
\hline$\left(\mathrm{CF}_{3}\right)_{2} \mathrm{CHOY} \rightarrow\left(\mathrm{CF}_{3}\right)_{2} \mathrm{CO}$ & & 336 & 135 & 11 & -36 \\
\hline $\mathrm{CH}_{3} \mathrm{CH}_{2} \mathrm{CH}_{3} \rightarrow \mathrm{CH}_{3} \mathrm{CH}=\mathrm{CH}_{2}$ & 124 & & 150 & 5 & -36 \\
\hline $\mathrm{CF}_{3} \mathrm{CH}_{2} \mathrm{CH}_{3} \rightarrow \mathrm{CF}_{3} \mathrm{CH}=\mathrm{CH}_{2}$ & 146 & & 169 & 7 & -35 \\
\hline
\end{tabular}

${ }^{a}$ Reference 16. ${ }^{b}$ Basis set superposition error estimated by counterpoise. ${ }^{c}$ Unscaled. ${ }^{d}$ Refers to a geometry in which the $\mathrm{O}-\mathrm{Y}$ bond is antiperiplanar to a fluorinated methyl group and a $\mathrm{C}-\mathrm{F}$ bond is antiperiplanar to the oxygen. ${ }^{e} \mathrm{~A} 10.52 \mathrm{~kJ} / \mathrm{mol}$ electronic energy difference between synclinal and antiperiplanar conformations, as compared to a $10.95 \mathrm{~kJ} / \mathrm{mol}$ electronic energy difference calculated for geometries optimized at B3LYP/6-31+G* (Schaal, H.; Haeber, T.; Suhm, M. A. J. Phys. Chem. A 2000, 104, 265-274).

elimination of $\mathrm{Li}-\mathrm{H}$ from substituted lithium alkoxides if the most stable conformation of the lithium alkoxides are used, eq 6. However, both the fluorinated alcohols and the fluorinated lithium alkoxides exhibit attractive intramolecular interactions between fluorine and the substituent attached to oxygen $(\mathrm{H}$ in the case of the alcohols and $\mathrm{Li}$ in the case of the lithium alkoxides). If we use DFT to calculate $\Delta E^{\mathrm{el}}$ for alcohol dehydrogenation using the less stable conformational isomers in which this interaction is absent, the correlation with the $\Delta E_{\text {act }}$ remains poor for the lithium alkoxides but improves for the alcohols. Similarly we find poor correlations of $\Delta E_{\text {act }}$ with $\Delta E^{\mathrm{el}}$ for the fluorinated 2-propanols and the lithium isopropanoxides in their most favorable conformations, but $\Delta E_{\text {act }}$ displays an excellent correlation with $\Delta E^{\mathrm{el}}$ for dehydrogenation of the 2-propanols when reactant conformations have the $\mathrm{O}-\mathrm{H}$ bond antiperiplanar to a fluorinated methyl group. The two linear plots are drawn in Figure 6. Note that the electronic energy difference, $\Delta E^{\mathrm{el}}$, for methanol dehydrogenation does not fall on either of these lines.

\section{Discussion}

Isotope Effects and the $\boldsymbol{\beta}$-Hydrogen Elimination Mechanism. This work provides a deeper understanding of the nature of the transition state for $\beta$-hydrogen elimination on metal surfaces. The approach has been to use fluorine substitution in alkoxy and alkyl groups on the $\mathrm{Cu}(111)$ surface as a means of perturbing the reaction energetics. The effects of fluorine substitution are then used to probe the nature of the transition state. The measurements of deuterium isotope effects presented in this paper serve to justify some of the assumptions implicit in the use of substituent effects to study reaction energetics. The isotopic $\Delta \Delta E_{\text {act }}$ values determined from intermolecular DKIE measurements are $4.0 \pm 0.7 \mathrm{~kJ} \mathrm{~mol}^{-1}$ for ethoxy and 4.4 $\pm 0.8 \mathrm{~kJ} \mathrm{~mol}^{-1}$ for trifluoroethoxy. These do not differ significantly from one another, supporting the conclusion that fluorination of the methyl group in ethoxy does not alter the reaction mechanism and that the $\beta$-hydrogen elimination step is rate limiting in both species. Furthermore, in agreement with previous measurements of $\beta$-hydrogen elimination in methoxy species on the $\mathrm{Cu}(110)$ surface, ${ }^{22}$ we find no evidence for secondary isotope effects. The net implication of these observations is to support our discussion below that describes the effects

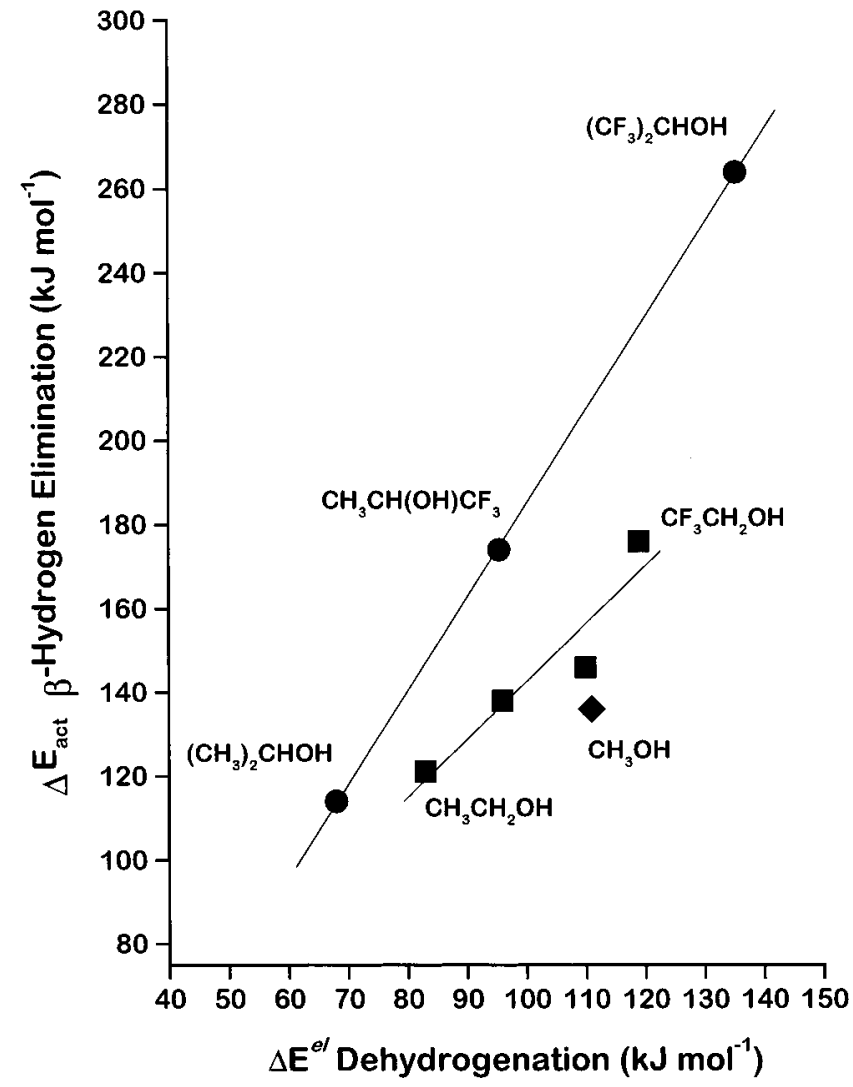

Figure 6. Correlation between $\Delta E_{\text {act }}$ for $\beta$-hydrogen elimination in alkoxides on $\mathrm{Cu}(111)$ to $\Delta \mathrm{E}^{\mathrm{el}}$ for alcohol dehydrogenation in the gas phase. The alcohols have conformations in which the $\mathrm{O}-\mathrm{H}$ bond is antiperiplanar to a fluorinated methyl. The separate lines for ethoxy groups and isopropoxy groups indicate that substitution at the carbinol carbon affects the transition state of $\beta$-hydrogen elimination on the surface but that within a given series the transition state is more sensitive to fluorination than are the overall energetics. The data point corresponding to methanol does not lie on either line.

of fluorination on the $\Delta E_{\text {act }}$ to $\beta$-hydrogen elimination in terms of electronic effects which energetically destabilize the transition state with respect to the reactant alkoxy species.

The Transition State for $\boldsymbol{\beta}$-Hydrogen Elimination. The nature of the transition state for $\beta$-hydrogen elimination proposed 


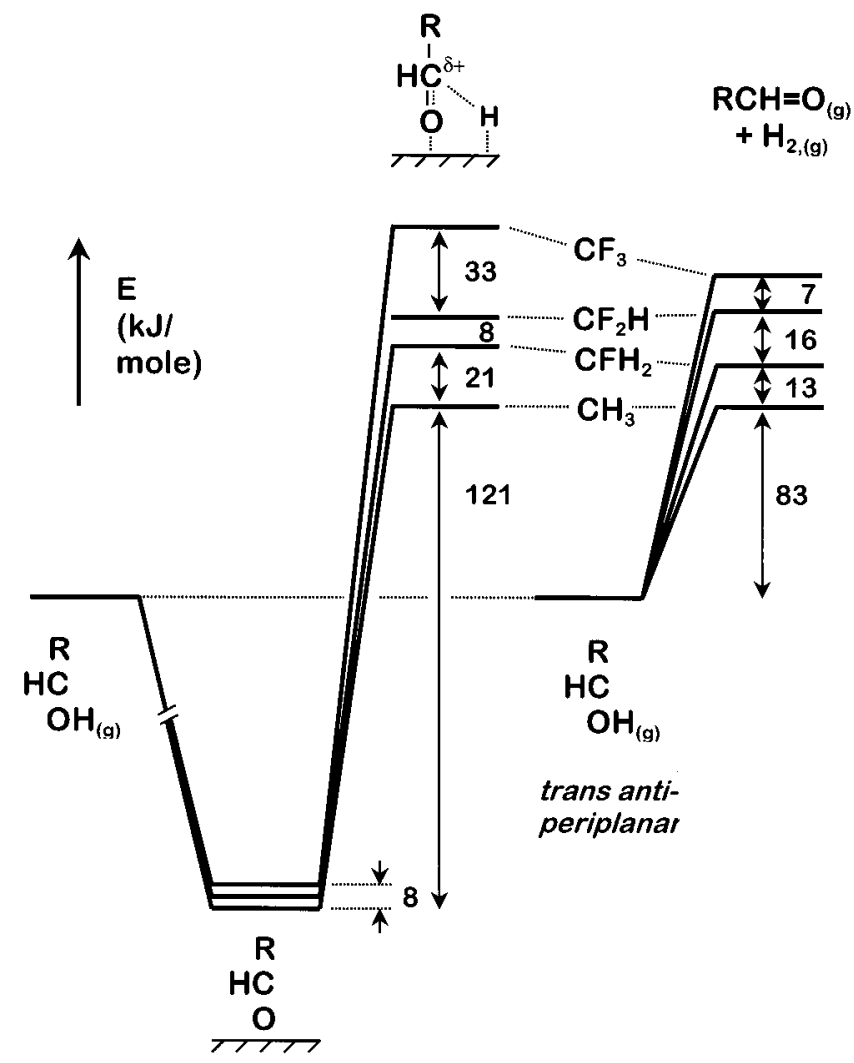

Figure 7. One-dimensional potential energy diagram showing the effects of fluorination on the $\Delta E_{\text {act }}$ to $\beta$-hydrogen elimination in ethoxides on the $\mathrm{Cu}(111)$ surface. The left-hand side of the diagram illustrates the energetics for formation of ethoxy groups from gas-phase alcohols and the subsequent reaction via the transition state to $\beta$-hydrogen elimination. At the right are the energetics for the gasphase dehydrogenation of the ethanols in their trans antiperiplanar conformations to acetaldehydes. The effects of fluorination map $\Delta \Delta E_{\text {act }}$ proportionately onto $\Delta \Delta E^{\mathrm{el}}$.

on the basis of previous results was one in which the $\beta$-carbon atom loses electron density due to the elimination of a hydridelike species $\left[\mathrm{RC}^{\delta+} \cdot \cdot \cdot \mathrm{H}^{\delta-}\right]^{\ddagger}{ }^{1,2}$ In this type of transition state, the $\beta$-carbon is electron deficient with respect to the reactant ethoxide, and fluorination of the methyl group (R) increases the $\Delta E_{\text {act }}$ by energetically destabilizing the charge distribution in the transition state. ${ }^{1}$ The results presented in this paper provide a deeper insight into the nature of the transition state. The $\beta$-hydrogen elimination energetics are illustrated in the potential energy diagram of Figure 7. The left-hand portion of the diagram shows the energetics for the reaction of substituted ethanols to form ethoxy groups followed by $\beta$-hydrogen elimination. The right side of the diagram shows the energetics for the gas-phase dehydrogenation of the ethanols to form acetaldehydes. Clearly, the effects of fluorine on the energy of the dehydrogenation reaction map onto the energies of the transition states for $\beta$-hydrogen elimination. This is illustrated in a more quantitative fashion by the plot in Figure 6 of $\Delta E_{\text {act }}$ versus calculated values of $\Delta E^{\mathrm{el}}$.

A question arises as to the importance of screening by the metal as a mechanism for influencing the magnitude of substituent effects. Electrostatic calculations have been made of the influence of conducting metal surfaces on substituent effects for $\beta$-hydrogen elimination from ethoxy groups (where the substituent is relatively far from the surface, $>3 \AA$ ). ${ }^{24}$ These indicate that the substituent effect on $\Delta E_{\text {act }}$ is not significantly influenced by the conducting nature of the metal surface.

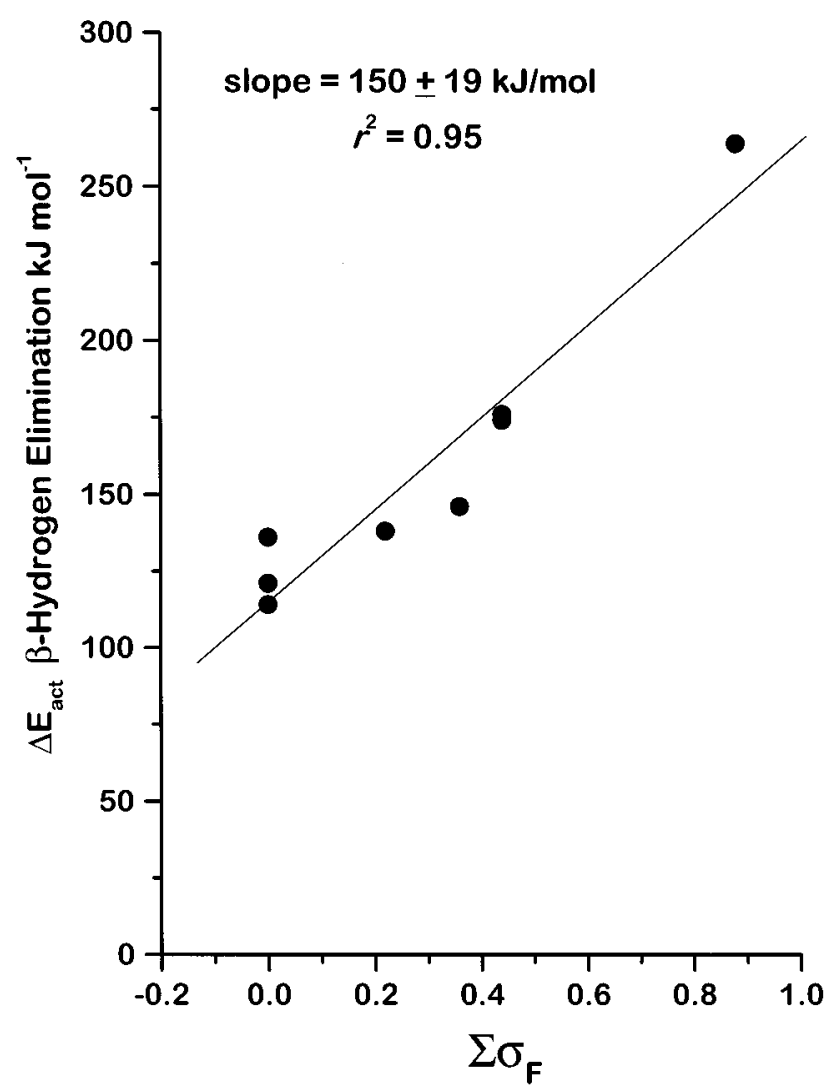

Figure 8. Linear free energy relationship correlating the barriers to $\beta$-hydrogen elimination in adsorbed alkoxides with the Hammett $\sigma_{\mathrm{p}}$ constants of the substituents attached to the carbinol carbon (cf. Table 1). The steep slope gives a Hammett reaction constant of $\rho=-26 \pm$ 3 that is consistent with substantial development of positive charge at the $\mathrm{C} 1$ carbon in the transition state.

The comparison of the $\Delta E_{\text {act }}$ for a surface reaction with theoretical estimates of $\Delta E^{\mathrm{el}}$ for the analogous gas-phase dehydrogenation reaction is only one approach to quantifying the effects of substituents on surface reaction energetics. A second approach that can be used to understand the effects of substituents in a wide range of reactions is to examine linear free energy relationships by means of empirically derived substituent constants. Such substituent constants have been tabulated through the study of a wide range of solution-phase and gas-phase organic reactions. ${ }^{15}$ They reflect empirical measures of a number of different properties of the substituents. Table 1 lists the traditional Hammett substituent constants $\left(\sigma_{\mathrm{p}}\right.$ and $\sigma_{\mathrm{F}}$ ) of the methyl and fluorinated methyl groups used as substituents on the alkoxy groups studied in this work. These have been used as measures of the properties of the substituents and can be correlated with the $\Delta E_{\text {act }}$, as illustrated in Figure 8.

The use of linear free energy relationships requires that entropy changes scale with energy changes. Plots of the logarithm of the frequency factor $v\left(\log _{10} v\right)$ versus $\Delta E_{\text {act }}$ give good linear correlations $\left(r^{2}>0.99\right)$, so that criterion is met. Figure 8 plots the $\Delta E_{\text {act }}$ for $\beta$-hydrogen elimination against the sum of the substituent constants $\left(\sum \sigma_{\mathrm{F}}\right)$ in a given alkoxy species and reveals a strong linear correlation between the two. There are a number of substituent constants to choose from. The field substituent constant, $\sigma_{\mathrm{F}}$, attempts to isolate the electrostatic field effect of a substituent on nearby charge. The venerable Hammett substituent constant, $\sigma_{\mathrm{p}}$, is an empirical measure of combined effects of resonance and electrostatic field of the substituent. Both give equally good fits to the set of $\Delta E_{\text {act }}$ measured in this work. Even better fits can be obtained by plotting linear free 
energy relationships independently for the $\Delta E_{\text {act }}$ measured for the ethoxy and isopropoxy groups. This might be expected from the correlations of Figure 6 which revealed some differences between the ethoxy and isopropoxy groups. When the data for ethoxy and isopropoxy are plotted independently the correlation using the $\sigma_{\mathrm{p}}$ constants is better than that obtained using just the $\sigma_{\mathrm{F}}$ constants. The interpretation of Figure 8 is that the fluoromethyl groups interact by electrostatic field effects with a $\beta$-carbon which is electron deficient in the transition state. The slope of the linear free energy relationship is $150 \pm 19 \mathrm{~kJ} \mathrm{~mol}^{-1}$ which converts into a reaction constant of $\rho=-26 \pm 3$. For comparison a large value of $\rho(\sim 12)$ was recently measured for a gas-phase hydride transfer equilibrium reaction. ${ }^{25}$ This use of substituent parameters points to a simple approach for accounting for substituent effects that can be used to correlate effects on surfaces with those observed in other environments such as the gas phase or solution.

Reaction Energetics for $\boldsymbol{\beta}$-Hydrogen Elimination. On the basis of the arguments above, we propose that the transition state for $\beta$-hydrogen elimination occurs late in the reaction coordinate. Hammond's postulate suggests that the transition states for exothermic reactions should be reactant-like, while the transition states for endothermic reactions should be productlike. ${ }^{26}$ The overall reaction energetics for ethoxy conversion to adsorbed acetaldehyde on the $\mathrm{Cu}(111)$ surface are not known. However, the implication of the proposed late transition state is that the reaction is endothermic. We can estimate the energetics on the $\mathrm{Cu}(111)$ surface using the following hypothetical reaction path:

$$
\begin{gathered}
\mathrm{CH}_{3} \mathrm{CH}_{2} \mathrm{OH}_{(\mathrm{g})} \rightarrow \mathrm{CH}_{3} \mathrm{CH}_{2} \mathrm{O}_{(\mathrm{g})}+\mathrm{H}_{(\mathrm{g})} \\
\Delta H_{1}=437.7 \pm 3.4 \mathrm{~kJ} \mathrm{~mol}^{-1} \\
\mathrm{CH}_{3} \mathrm{CH}_{2} \mathrm{O}_{(\mathrm{g})} \rightarrow \mathrm{CH}_{3} \mathrm{CH}_{2} \mathrm{O}_{(\mathrm{ad})} \\
\Delta H_{2}<-264 \mathrm{~kJ} \mathrm{~mol}^{-1} \\
\mathrm{CH}_{3} \mathrm{CH}_{2} \mathrm{O}_{(\mathrm{ad})} \rightarrow \mathrm{CH}_{3} \mathrm{CH}=\mathrm{O}_{(\mathrm{ad})}+\mathrm{H}_{(\mathrm{ad})} \\
\Delta H_{\beta-\mathrm{H}} \\
\mathrm{CH}_{3} \mathrm{CH}=\mathrm{O}_{(\mathrm{ad})} \rightarrow \mathrm{CH}_{3} \mathrm{CH}=\mathrm{O}_{(\mathrm{g})} \\
\Delta H_{4}=56 \pm 8 \mathrm{~kJ} \mathrm{~mol}^{-1} \\
\Delta H_{5}=230 \pm 16 \mathrm{~kJ} \mathrm{~mol}^{-1} \\
\Delta H_{6}=-436 \mathrm{~kJ} \mathrm{~mol}^{-1} \\
\mathrm{H}_{(\mathrm{ad})} \rightarrow \mathrm{H}_{(\mathrm{g})} \\
2 \mathrm{H}_{(\mathrm{g})} \rightarrow \mathrm{H}_{2,(\mathrm{~g})} \\
\hline \mathrm{CH}_{3} \mathrm{CH}_{2} \mathrm{OH}_{(\mathrm{g})} \rightarrow \mathrm{CH}_{3} \mathrm{CH}=\mathrm{O}_{(\mathrm{g})}+\mathrm{H}_{2,(\mathrm{~g})} \\
\Delta H_{\mathrm{rxn}}=64.6 \pm 1.6 \mathrm{~kJ} \mathrm{~mol}^{-1}
\end{gathered}
$$

The point of decomposing the thermodynamic cycle for the dehydrogenation of ethanol in this manner is to estimate the heat of reaction for step $3\left(\Delta H_{\beta-\mathrm{H}}\right), \beta$-hydrogen elimination on the $\mathrm{Cu}(111)$ surface. $\Delta H_{1}$ and $\Delta H_{6}$ were obtained from the appropriate bond strengths. ${ }^{27}$ The desorption energy of the alkoxy $\left(\Delta H_{2}\right)$ must be greater than the barrier to $\beta$-hydrogen elimination of $\left(\mathrm{CF}_{3}\right)_{2} \mathrm{CHO}_{(\mathrm{ad})}$ (otherwise it would desorb rather than undergoing $\beta$-hydrogen elimination); therefore, $\Delta H_{2}$ must be less than $-264 \mathrm{~kJ} \mathrm{~mol}^{-1}$. This assumes that the alkoxy bond strength to the metal is unaffected by fluorination of the methyl groups. This is justified on the basis of measurements of the relative heats of formation of ethoxy and trifluoroethoxy on the $\mathrm{Cu}(111)$ surface from their corresponding alcohols. The desorption energy of acetaldehyde, $\Delta H_{4}$, was found in the literature. ${ }^{20} \Delta H_{5}$ is estimated from the hydrogen bond strength ${ }^{27}$ and the desorption energy of hydrogen. ${ }^{28}$ It has also been reported by B. E. Bent and co-workers. ${ }^{29}$ These energies provide an estimate of the heat of reaction for $\beta$-H elimination in ethoxy of $\Delta H_{\beta-\mathrm{H}}>41 \pm 18 \mathrm{~kJ} \mathrm{~mol}^{-1}$. It has also been possible to estimate the energetics for another relevant $\beta$-hydrogen elimination reaction, the conversion of propyl groups to adsorbed propene by $\beta$-hydrogen elimination on the $\mathrm{Cu}(100)$ surface. ${ }^{28}$ In that case the heat of reaction of $\beta$-hydrogen elimination in propyl groups has been estimated at $\Delta H_{\mathrm{rxn}}=27 \pm 15 \mathrm{~kJ} \mathrm{~mol}^{-1}$. The reaction energetics are probably quite similar on the $\mathrm{Cu}(111)$ surface. Within the context of a discussion based on Hammond's postulate, it should be noted that the endothermicity of the $\beta$-hydrogen elimination reaction in both the alkoxy and the alkyl groups is consistent with our proposal that the transition state occurs late in the reaction coordinate. It should be noted that the substituent effects observed for $\beta$-hydrogen elimination in the ethoxy groups on the $\mathrm{Cu}(111)$ surface have also been observed with the same magnitude on the $\mathrm{Cu}(100)$ surface and on the $\operatorname{Ag}(110)$ surface. ${ }^{1}$ Thus, it is quite likely that in all these cases $\beta$-hydrogen elimination is endothermic and occurs with a late transition state.

$\boldsymbol{\beta}$-Hydrogen Elimination in Alkoxy versus Alkyl. The deeper insight offered by these results regarding the nature of the transition state for $\beta$-hydrogen elimination also offers a plausible explanation for the differences between the substituent effects observed in alkoxy and in alkyl groups on the $\mathrm{Cu}(111)$ surface. The $\Delta E_{\text {act }}$ for $\beta$-hydrogen elimination in $\mathrm{CH}_{3} \mathrm{CH}_{2} \mathrm{O}_{(\mathrm{ad})}$ increases by $\Delta \Delta E_{\text {act }}=55 \mathrm{~kJ} \mathrm{~mol}^{-1}$ as a result of perfluorination of the methyl group. However, perfluorination of the methyl group in $\mathrm{CH}_{3} \mathrm{CH}_{2} \mathrm{CH}_{2}$,(ad) increases the $\Delta E_{\text {act }}$ for $\beta$-hydrogen elimination by only $\Delta \Delta E_{\text {act }}=35 \mathrm{~kJ} / \mathrm{mol}$. These differences are also reflected in the heats of the gas-phase dehydrogenation reactions for alcohols and alkanes. DFT calculations predict that perfluorination of the methyl group results in a $\Delta \Delta E^{\mathrm{el}}=36 \mathrm{~kJ}$ $\mathrm{mol}^{-1}$ for ethanols in their trans conformations but only $19 \mathrm{~kJ} /$ mol in going from propane to trifluoropropane (the experimental heat of hydrogenation of trifluoropropene is not available). The ratio $\Delta \Delta E_{\text {act }} / \Delta \Delta E^{\mathrm{el}}(=1.8)$ in going from propane to $1,1,1-$ trifluoropropane is close to that observed on going from ethanol to trans-1,1,1-trifluoroethanol $\left(\Delta \Delta E_{\mathrm{act}} / \Delta \Delta E^{\mathrm{el}}=1.5\right)$. In our view, this warrants the conclusion that the same electronic effects operate in dehydrogenation of surface-bound alkyl groups as in alkoxy groups. In the alkoxy case, the reaction results in the formation of a $\mathrm{C}=\mathrm{O}$ double bond from what originally was a $\mathrm{C}-\mathrm{O}$ single bond in the ethoxy reactant. In the alkyl case, the reaction results in the formation of a $\mathrm{C}=\mathrm{C}$ double bond from what was a $\mathrm{C}-\mathrm{C}$ single bond in the propyl reactant. The substituent effect reflects differences in the charge density on the $\beta$-carbon on going from reactant to product. The fact that these ratios are $\Delta \Delta E_{\mathrm{act}} / \Delta \Delta E^{\mathrm{el}}>1$ is interesting. Apparently, a greater partial positive charge develops in the transition state than in the final product.

Substitution at the Carbinol Carbon. The ratio $\Delta \Delta E_{\text {act }}$ $\Delta \Delta E^{\mathrm{el}}$ in going from 2-propanol to 1,1,1-trifluoro-2-propanol $(=2.2)$ is greater than for the substituted ethanols $(=1.5)$. Given that the plot for the isopropoxy groups in Figure 6 has a steeper slope than for the ethoxy groups, it appears that a combination of effects operate for isopropoxy groups. On one hand, a greater partial positive charge develops in the dehydrogenation of secondary alkoxy groups than in primary alkoxy groups. This is consistent with the qualitative electronic effect expected with increasing substitution at the reacting center. On the other hand, the ratio $\Delta \Delta E_{\text {act }} / \Delta \Delta E^{\mathrm{el}}$ in going from ethanol to 2-propanol is 
0.5 and has a value comparable to the ratio in going from methanol to ethanol $\left(\Delta \Delta E_{\mathrm{act}} / \Delta \Delta E^{\mathrm{el}}=0.5\right)$. Apparently steric effects attenuate the electronic effects of increasing alkyl substitution at the carbinol carbon.

\section{Conclusions}

The $\beta$-hydrogen elimination reaction of fluorine-substituted alkoxy groups on the $\mathrm{Cu}(111)$ surface yields the corresponding aldehydes and ketones. Three relationships between kinetics and thermochemistry have been explored: deuterium isotope effects, fluorine substituent effects, and increasing alkyl substitution at the carbinol center. Deuterium kinetic isotope effects are of roughly the same magnitude for both ethoxy and trifluoroethoxy. This indicates that the $\beta$-hydrogen elimination step is rate limiting in both species. Experimental $\Delta \Delta E_{\text {act }}$ values scale linearly with $\Delta \Delta E^{\mathrm{el}}$ for gas-phase dehydrogenation for alcohols in their trans antiperiplanar conformations, with a constant of proportionality of $>1$. The same scaling is found when the distal carbon of an $n$-propyl group is fluorinated, but experimental $\Delta E_{\text {act }}$ for unfluorinated alcohols do not give such a good linear correlation with increasing methyl substitution at the reacting center (i.e., methoxy $\rightarrow$ ethoxy $\rightarrow$ isopropoxy, where $\Delta \Delta E_{\text {act }}$ scales with $\Delta \Delta H_{\mathrm{rxn}}$ by a factor of $\leq 0.5$ ).

The correlations between kinetics and thermochemistry exhibit a variety of trends. The observed kinetic isotope effects indicate that dehydrogenation on the $\mathrm{Cu}(111)$ surface reaches the top of the barrier at a point where the alkoxy $\mathrm{C}-\mathrm{H}$ bond has dissociated to a substantial extent (i.e., a late transition state). The correlation between $\Delta E_{\text {act }}$ and calculated gas-phase $\Delta E^{\mathrm{el}}$ for dehydrogenation of fluorinated ethanols in their trans antiperiplanar conformations contrasts with the poorer correlations based on thermochemistry of their most stable conformations or on the thermochemistry calculated for elimination of $\mathrm{LiH}$ from lithium ethoxides (regardless of conformation). This suggests that on the surface the oxygen-metal bond is antiperiplanar to a fluorinated carbon and that the oxygen is antiperiplanar to one of the fluorines. This interpretation accords with the experimental finding that fluorination does not greatly perturb binding to the metal surface. The effect of fluorination does not arise from stabilization of the adsorbed alkoxy reactant but is instead a consequence of developing positive charge on the $\beta$-carbon in the transition state $\left[\mathrm{RC}^{\delta+} \cdot \cdot \mathrm{H}\right]^{\ddagger}$. A similar effect is observed for $\beta$-hydrogen elimination from adsorbed alkyl groups, where the same type of charge buildup on carbon must be taking place. The net result is that the $\Delta E_{\text {act }}$ are $1.5-2.2$ times more sensitive to fluorine substitution than is the overall $\Delta E^{\mathrm{el}}$ for the analogous gas-phase dehydrogenation reactions.

Alkyl substitution at the carbinol carbon has two opposing effects. On one hand, it stabilizes the emerging positive charge at the carbinol carbon atom in the transition state. On the other hand, it creates steric hindrance at the reacting center. The net result is that the $\Delta E_{\text {act }}$ are less sensitive to methyl substitution than is the overall thermochemistry. Finally, good linear correlations are obtained between $\beta$-hydrogen elimination rates and Hammett substituent parameters $\left(\sigma_{\mathrm{p}}\right.$ or $\left.\sigma_{\mathrm{F}}\right)$, which take into account both resonance and electric field effects.

Acknowledgment. This paper is dedicated to Professor W. A. Goddard III. This work was supported by NSF Grants CHE9701924 and CHE 9522604. M. T. Buelow was supported by a fellowship from the Shell Foundation.

\section{References and Notes} 722

(1) Gellman, A. J.; Dai, Q. J. Am. Chem. Soc. 1993, 115 (2), 714-

(2) Forbes, J. G.; Gellman, A. J. J. Am. Chem. Soc. 1993, 115 (14), $6277-6283$

(3) Weldon, M. K.; Friend, C. M. Chem. Rev. 1996, 96 (4), 13911412

(4) Friend, C. M.; Xu, X. Annu. Rev. Phys. Chem. 1991, 42, 251-

(5) Zaera, F. Chem. Rev. 1995, 95 (8), 2651-2693

(6) Zachariah, M. R.; Westmoreland, P. R.; Burgess, D. R., Jr.; Tsang, W.; Melius, C. F. J. Phys. Chem. 1996, 100, 8737-8747.

(7) (a) Domalski, E. A.; Hearing, E. D. J. Phys. Chem. Ref. Data 1993 22, 805-1159. (b) Afeefy, H. Y.; Liebman, J. F.; Stein, S. E. Neutral Thermochemical Data. In NIST Chemistry WebBook; Mallard, W. G., Linstrom, P. J., Eds.; NIST Standard Reference Database Number 69; National Institute of Standards and Technology: Gaithersburg, MD, November 1998 (http://webbook.nist.gov).

(8) Joshi, R. M. J. Macromol. Sci. Chem. 1974, 8, 861-865

(9) Xu, L.-H.; Fraser, G. T.; Lovas, F. J.; Suenram, R. D.; Gillies, G. W.; Warner, H. E.; Gillies, J. Z. J. Chem. Phys. 1995, 103, 9541-9548. 7170

(11) Xu, J.; Zhang, X.; Zenobi, R.; Yoshinobu, J.; Xu, Z.; Yates, J. T., Jr. Surf. Sci. 1991, 256, 288-300.

(12) Street, S. C.; Gellman, A. J. J. Phys. Chem. 1996, 100 (20), 83388348 .

(13) Teplyakov, A. V.; Bent, B. E. J. Am. Chem. Soc. 1995, 117 (40), 10076-10087.

(14) Higashi, G. S.; Raghavachari, K.; Steigerwald, M. L. J. Vac. Sci. Technol. B 1990, 8, 103-105.

(15) Hansch, C.; Leo, A.; Taft, R. W. Chem. Rev. 1991, 91 (2), 165195.

(16) Curtiss, L. A.; Raghavchari, K.; Redfern, P. C.; Rassolov, V.; Pople, J. A. J. Chem. Phys. 1998, 109, 7764-7776.

(17) Hagen, K.; Hedberg, K. J. Am. Chem. Soc. 1973, 95, 8263-8266.

(18) Xu, L.-H.; Fraser, G. T.; Lovas, F. J.; Suenram, R. D.; Gillies, C. W.; Warner, H. E.; Gillies, J. Z. J. Chem. Phys. 1995, 103, 9541-9548.

(19) Marstokk, K. M.; Møllendahl, H. Acta Chem. Scand. Ser. A 1980, $34,765-770$

(20) Bowker, M.; Madix, R. J. Appl. Surf. Sci. 1981, 8, 299

(21) Madix, R. J.; Telford, S. G. Surf. Sci. 1992, 277, 246-252.

(22) Madix, R. J.; Telford, S.G. Surf. Sci. 1995, 328, L576-L581.

(23) Zachariah, M. R.; Westmoreland, P. R.; Burgess, D. R., Jr.; Tsang, W.; Melius, C. F. J. Phys. Chem. 1996, 100, 8737-8747.

(24) Buelow, M. T.; Gellman, A. J. J. Phys. Chem., in press.

(25) Tashiro, H.; Kikukawa, K.; Ikenaga, K.; Shimizu, N.; Mishima, M. J. Chem. Soc., Perkin II 1998, 2435.

(26) Hammond, G. S. J. Am. Chem. Soc. 1955, 77, 334.

(27) Lide, D. R., Ed. CRC Handbook of Chemistry and Physics, 78th ed.; CRC Press: Boca Raton, 1997.

(28) Anger, G.; Winkler, A.; Rendulic, K. D. Surf. Sci. 1989, 220, 1-17.

(29) Jenks, C. J.; Xi, M.; Yang, M. X.; Bent, B. E. J. Phys. Chem. 1994, $98(8), 2152-2157$. 